\title{
BLENDED LEARNING MODEL IN THE INNOVATIVE ELECTRONIC BASIS OF TECHNICAL ENGINEERS TRAINING
}

\author{
Nadezhda Almazova, Anna Rubtsova, Elena Krylova, Darina Barinova, \\ Yuri Eremin \& Natalia Smolskaia
}

Peter the Great St. Petersburg Polytechnic University
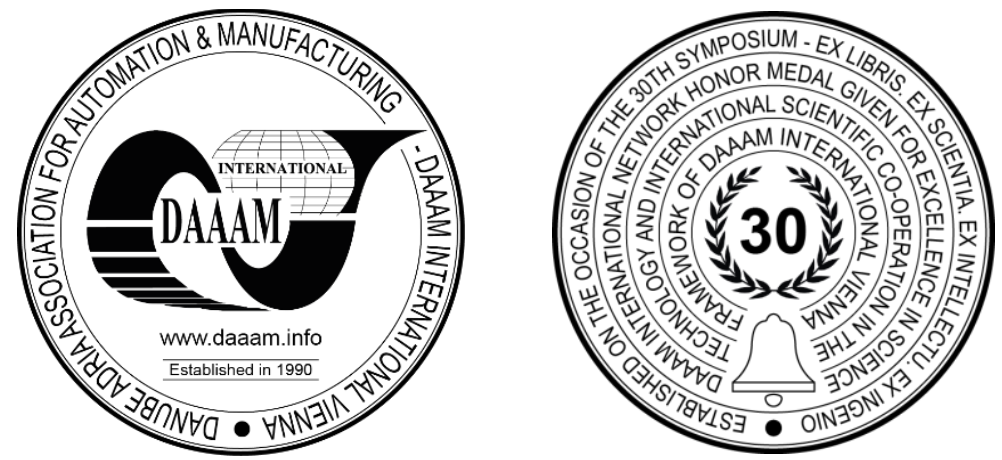

This Publication has to be referred as: Almazova, N[adezhda]; Rubtsova, A[nna]; Krylova, E[lena]; Barinova, D[arina]; Eremin, Y[uri] \& Smolskaia, N[atalia] (2019). Blended Learning Model in the Innovative Electronic Basis of Technical Engineers Training, Proceedings of the 30th DAAAM International Symposium, pp.0814-0825, B. Katalinic (Ed.), Published by DAAAM International, ISBN 978-3-902734-22-8, ISSN 1726-9679, Vienna, Austria

DOI: $10.2507 / 30$ th.daaam.proceedings.113

\begin{abstract}
The article proposes a solution to the problem of information and communication technologies applying in the training system of engineers. The methodological basis for the use of information and communication technologies is blended learning. Effective blended learning realization is caused by different factors which are identified by the authors on the university, teacher and student levels. The article proposes four functional models of blended learning: a supporting model, a replacement model, a mobile model, and a model of an electronic linguistic center. Results of the pedagogical experiment conducted in Peter the Great St. Petersburg Polytechnic University proved our hypothesis that supporting model of blended learning is the most appropriate and effective for training technical English and students' professional competence development. The main differences in the design of the blended learning model from traditional learning can be considered the choice of a blended learning model relevant to the goals, objectives and learning conditions, information and communication technologies as learning tools used in this model, as well as the distribution of educational material, types of cognitive activities and forms of work between full-time and remote component. Highlighted regulations can be considered the key to the creation or modification of any course on the blended learning model basis in the training system of engineers.
\end{abstract}

Keywords: information technology; blended learning; electronic; model; foreign language.

\section{Introduction}

Modern training system of engineers is unthinkable without the widespread use of innovative constantly developing information and communication technologies. However, lecturers and instructors should know the properties and the functions of all information technologies introducing in the educational process. That is why it is important to clearly define didactic problems and tasks which may solved by information and communication technologies (ICT) integrating with the specification of the special subject and applying within the holistic methodical approach as the basis for blended learning design [1].

Application of ICT in the educational process and new pedagogical models, such as blended learning, should be caused by the social order and actual socio-economic needs of the society. In the modern information society, characterized by 
huge accumulation of information, traditional education is unable to cope with its tasks using the old instructive methods. The solution to the problem of modernizing education lies in its computerization and informatization, therefor it is obvious that ICT is simply necessary in organizing the educational process, because each university has the task of intensifying and improving the quality of education in order to train highly qualified and competitive specialists [2].

A number of scientists believe that the didactic properties of ICT are based on the two most important functions: informational and communicative. These functions can manifest themselves in all stages of the educational process.

Despite the obvious advantages of blended learning, it is impossible, however, not to admit that its effective functioning is possible only when the use of this form of education in the educational process is methodologically justified [3], [4], [5].

The purpose of this research is to describe the factors causing the effective and successful application of blended learning in the teaching of foreign languages and appropriate methodical models of blended learning in teaching foreign languages in technical universities.

Our practical experience and analysis of scientific papers showed that factors of effective blended leaning realization can be divided into three groups:

1) university level factors;

2) teacher level factors;

3) student level factors.

\section{University level factors for effective blended learning applying}

As the practice shows following tasks are assigned to modern institutions of higher education:

1. Development and implementation of a long-term, well-planned strategy for using ICT in education, based on an analysis of existing practical experience in this field, both in Russia and abroad. It can be implemented at the level of the entire university, faculties and specific training courses, in particular, linguistic.

2. The next prerequisite for the integration of technology into education is the creation and development of effectively designed information and educational environment of the university and its departments. In this regard, it should be noted that when developing electronic information and education environment (EIEE), such factors should be taken into account: the cost and availability of technologies that are inextricably linked with the monetary costs of their acquisition and maintenance [6].

When new information and communication technologies first appear on the market, their cost is very high, but after a short period of time, their price begins to fall due to the increasing popularity and mass character of their use (this was the case, for example, with the first CDs). Nowadays, the use of multimedia projectors in training is becoming popular, they are becoming more and more accessible, while interactive boards, despite all their advantages, are only beginning to occupy their niche in Russia because of the relatively high cost.

Many universities in Russia and abroad today prefer to develop EIEE by using MOODLE, Optima, ILIAS, aTutor, Blackboard Learning System and etc. There is also the issue of information security of education, which is a mandatory component of the EIEE of the university in the context of the massive introduction of ICT. This problem causes focused activities of specialists to achieve the state of protection of the information environment of the educational institution, ensuring its normal functioning and dynamic development. It requires the availability of qualified technical staff for all areas, especially humanities. Focusing on the last factor, we should focus on the problem of training special instructors, competent in the sphere of linguistics and special technical field: teachers and course developers in the framework of blended learning. Perhaps this division may not seem quite obvious, since at the moment most teachers are also developers of training courses in the form of blended learning. This problem is connected with the lack of qualified specialists, developing training courses in the form of blended learning, since its implementation is carried out on the basis of individual attempts to introduce this pedagogical model into the educational process [7].

Regarding teachers, it is worth noting that for conducting training courses in the form of blended learning, first of all, they must have sufficient motivation that management can create by conducting regular psychological training (it is especially important for those who have never used technology and are technophobic), seminars on ICT competence development and familiarization with the specifics of this pedagogical model, organization of access to various electronic resources related to the use of mixed learning in language courses, etc.

Many researchers note that creating training courses in the form of blended learning teachers spend a lot of personal time searching for and organizing material, communicating with students online: on forums, in chat rooms, blogs, via email, etc. Therefor educational institutions are encouraged to develop a system of incentives and rewards for those teachers who use blended learning in the educational process. According to statistics based on a study ${ }^{1}$ purposed to reveal how lecturers who teach students in the form of blended learning are encouraged, on average $14 \%$ of respondents answered that they did not receive any encouragement, $86 \%$ believed that this was part of their professional activities. At the same time, only an average of $26 \%$ receive a cash allowance, and for $23 \%$, the reduction of study hours was a reward [9].

${ }^{1}$ The study involved 68 teachers from several Russian universities. 
We analyzed numerous articles devoted to blended learning. The authors of these papers are mainly teachers themselves. We identified that few modern universities can afford to have a team of course developers. Therefore, the task of distributing the material, as well as the types of learning activities between the full-time and distance components, the choice of a blended learning model suitable for a language course, the development of a control system and criteria for evaluating the effectiveness of the course are the exclusive prerogative of teachers.

If such a team does exist, then all the above tasks should certainly be solved in direct contact with the teacher, since only he fully knows the specifics of the subject (foreign language). Important tasks facing the university are also feedback from students, monitoring of the educational process in the framework of blended learning, and publicizing the results in order to enhance the effectiveness of training.

\section{Teacher level factors for effective blended learning applying}

Considering the conditions for integrating blended learning into the educational process, which are within the competence of the university, inevitably factors relevant to the "level" of teachers should be considered, such as motivation, increasing ICT competence, familiarity with the specifics of the methodical model, etc. There are also other factors affecting the effectiveness of the use of this pedagogical model, concerning the teacher.

Firstly, this is a change in the teacher's role within the educational process. Organization of classes using blended learning requires high professionalism from the teacher. The teacher acts as a consultant, adviser, "manager", coordinator of the educational process, and not a "translator" of educational information. The teacher, conducting the course in the form of blended learning, is in constant contact with students, both in full-time classes and in the electronic medium of communication. It is worth noting that, despite the fact that such continuous communication can be quite time-consuming for the teacher, however, it is very effective. Constant feedback contributes to the teachers and students emotion formation of mutual involvement in the educational process, providing increase the motivation of both parties [8], [9], [10].

Secondly, a significant factor is the level of computer technology skills and information competence of the teacher. In this regard, it is appropriate to consider teachers' experience with information and communication technologies, in general, and with educational information technologies, in particular. For example, the instructor should know how to work with electronic dictionaries, interactive educational programs, such as Macmillan English Campus and etc.

There are several levels of ICT proficiency. First of all, a teacher who uses telecommunication technologies must have basic user skills, such as: search for quality educational resources that are useful for students, knowledge of interactive programs which may be recommended to students for independent usage, ability to use and effectively teach students to work with electronic dictionaries and reference books, electronic libraries and encyclopedias, etc. If the instructor has these basic skills and abilities, he can expand the arsenal of the information technologies by using Power Point, interactive whiteboard in the classroom and other electronic tools of education. At an advanced level, teachers can create their own online materials, tests, podcasts, use forums, blogs, chat rooms in training, conduct audio and video conferences, etc. [11], [12].

It should also be emphasized that the attitude of the teacher and students to the use of ICT in the educational process, which can be positive, negative or neutral, plays an important role in the integration of blended learning in the education. This position largely depends on the level of participants' skills to use information and communication technologies in the educational process, on their understanding of the opportunities of this pedagogical model providing educational process optimization. Teachers who do not have sufficient experience with the blended learning model can often experience fear of students being unmotivated and uncertainty about the effectiveness of conducting classes in this form.

Positive attitude of teachers and students to the use of ICT in the educational process can be formed by seminars and trainings dedicated to information literacy, familiarization with the features of this model, explaining the goals of using each tool, type of electronic communication or web-based tasks separately, etc. Communicating with other teachers conducting such courses in order to share experiences can also positively affect the success of integrating ICT into the educational process. It may be provided by personal conversations, as well as on specialized forums and chat rooms: Forum of English Language Teachers, The ScholarStuff Chat Network, ELT Russia and others.

\section{Student level factor for effective blended learning applying}

ICT integration into the educational process entails not only the development of new interactive methods of teaching, but also changes pedagogical process concerning students who are accustomed to the traditional full-time education system. The lack of student's skills for the intensive use of information technology in the educational process can be one of the obstacles to the successful application of blended learning.

In this regard, the formation and development of computer literacy should begin at secondary school. At present, a new generation of people growing up in the electronic environment is gradually emerging. In foreign sources, they are called "digital natives", "net generation", "millenials" [13]. In the Russian tradition the term is also not established - "born in the digital world", "digital native", "digital from birth", "digital person" [14].

The above-mentioned phenomena are especially important to consider when it comes to the use of ICT in the educational process, since modern pupils and students, on the one hand, and teachers and instructors, on the other, are, respectively, "digital natives" and "digital immigrants". They grew up in different eras and "speak different languages", 
which leads to misunderstanding, and if we consider this issue more globally, then, one can speak about quality reduction of educational results.

An important factor in the successful use of blended learning in the educational process is the degree of autonomy and the formed sustained motivation for learning and cognitive activity of students. In the conditions of Russian higher education modernization the reduction of academic hours is occurring. Therefore, students' independent autonomous learning is actualized. In connection with these changes, the status of a subject of the educational process acquired by a student makes him an equal participant in this process [15].

We should notice that blended learning allows students with different temperaments and different learning styles to master learning material equally well and provides an opportunity to express themselves in connection with a variety of forms of work. For example, students who rarely participate in discussions taking place in classroom classes, due to their shyness, fear of public speaking, or lack of time to think about their answer, are more likely to participate in online discussions, as they can have enough time to prepare the answer and to be more confident because they don't see an audience in front of them.

\section{Blended learning models}

Analysis of practical blended learning usage in technical English teaching, as well as scientific literature allows us to present classification of blended learning models developed on the basis of the following criteria:

1. the use of on-line format of communication learning;

2. determination of the professional communicative part of the training content;

3. change in the percentage of time allotted for classroom study, for independent work and for monitoring the progress of the educational process [9], [12], [20], [21], [22].

Thus, we distinguish for models of blended learning in teaching foreign languages to technical engineers:

1. supporting model;

2. replacement model;

3. mobile model;

4. electronic linguistic center model.

\subsection{Supporting model of blended learning}

Supporting model of blended learning in foreign languages education includes a distant communication component as a supplement to the system of traditional full-time study. This component may be consisted of linguistic task for group or individuals in a computer environment, complex training program, etc. It may also integrate the full-time learning into distance learning by organizing optional communication classes to consolidate and develop educational linguistic material.

This model provides some changes in the course format, despite the partial ICT integration into the traditional educational process. Traditional full-time education prevails, the number of classroom hours is maintained, but by increasing the volume of the material being studied through the distant component the amount of time allotted for independent work is growing. The teacher is able to better control the individual learning process of each student (due to feedback, which is an integral part of the distance learning in general) [16].

The use of this version of the model is methodologically justified if:

- the information and educational environment of the university is not sufficiently developed (since in this interpretation of the supporting model of blended learning there is the lowest level of integration of components, the supporting component may exist separately, for example, as a full-fledged electronic educational resource or as a series of seminars);

- all participants of the pedagogical process are confident users of computer technologies and have developed information competence.

The teacher acts as a consultant, a "manager" of the educational process.

In the case of "embedding" into distance courses of active teaching methods used in full-time classes, changing the course format also implies a transition to a supporting blended learning model, if the number of classroom hours spent on practical development of knowledge and skills in distant form does not exceed $25 \%$ of the total time allotted for the development of this course. The principle linguistic material is still presented in the distance course, which involves the independent work of students. Full-time studies based on the use of active learning methods do not replace the distance component, but only complement the initial content of the course [17].

As practice shows it is better to use a supporting model of blended learning, in which the distant component is basic in conditions when:

- the university has a developed electronic educational environment;

- teachers and students have a high level of computer literacy;

- the interests of students who cannot attend full-time classes are not affected;

- the organization of full-time classes with the use of active methods is carried out by teachers who are competent in this sphere. 
The flexibility of this training model implies the ability to work with educational material at a convenient time with a comfortable pace. This feature of the supporting blended learning model is especially important in adult education, where one of the key factors is the reduction of the employee's separation time from the workplace. The advantage of blended learning in this case is the combination of independent learning with classroom instruction, i.e. the student does not experience a lack of personal communication with the teacher and other students, while being able to work at an individual pace. In traditional education, which follows curriculum and makes it impossible to adjust the educational process, students do not always have the opportunity to regularly interact with the teacher and other students because of the prevalence of explanatory, illustrative and reproductive methods.

In this context, we note another problem of traditional full-time education, which is connected with teaching materials selection prepared in accordance with a strictly fixed curriculum. It means that individuality of each student is not taken into account. In such teaching conditions different degrees of interest in the subject, different abilities to master the linguistic material and many other important aspects are not considered. It reduces students' motivation in learning foreign language.

The blended learning model positively affects students' ability to independently navigate the flow of information, select and structure necessary material for work, training and personal development. In other words it develops students' learning autonomy as the ability to critical reflection, decision-making and independent activity.

An autonomous student is characterized by the fact that he/she is able to formulate his own learning goals, set priorities in learning tasks. He/she is able to find and independently create materials for his/her own education, to monitor and evaluate the success of the learning process. In particular, when teaching foreign languages, students with a developed autonomy better master a wide range of situational roles, which largely predetermines the essence of future communication. The constant interaction of students forms and develops the social and political competencies, identified by the Council of Europe among the eight basic competences that any specialists need today. These competencies are associated with the ability to take responsibility with a willingness to jointly solve various problems, both in academic terms and in a wider context.

As the practice shows blended learning implementation greatly increases students' learning motivation, as they are involved in active educational process and intensive cognitive activity. The student-centered approach used in the blended learning model allows you to develop the creative abilities of all students. Due to the variety of information presentation formats in the blended learning model, it can be stated that the training courses within this framework allow each student, regardless of his/her representative system, to be actively involved in the educational process.

Studies show that blended learning allows students with different types of temperaments to master learning material equally well and provides the opportunity to manifest themselves in connection with a variety of forms of work. For example, students who rarely take part in discussions taking place in the classroom, due to their shyness, fear of public speaking or lack of time to think about their answer, are more likely to participate in discussions held in online form.

What is more supporting blended learning allows all participants of the learning process to participate in the organization of classes. The teacher has the opportunity to build the learning process in such a way that students may study a certain part of the material independently using ICT (work with reference and information materials, independent search and research activities by using the Internet resources). Typically, in the classroom more attention is paid to practical activities that require direct contact with the teacher and groupmates. Students have the opportunity to participate in the formation of full-time classes, informing the teacher in advance through electronic communication about issues arising during the study of material in the course of independent work. Thus, the students and the teacher jointly adjusting the learning process in accordance with current needs.

In traditional learning, characterized by the predominance of explanatory-illustrative and reproductive methods, all teaching procedures are performed under the direct supervision of the teacher. As a result, students get overload memory due to the large amount of material reported in a relatively short time, while other mental processes, such as imagination, alternative and independent thinking is not always involved. This situation can lead to increased fatigue and loss of interest to learning.

As a rule, classes are conducted according to a fixed curriculum, where the teacher is both a source of knowledge and a main link in the transfer of this knowledge to students. It means that each student during a certain time, according to the received trajectory within the curriculum, moves from one stage to another. It is traditionally considered that in such training the volume of actually acquired knowledge, the quality and efficiency of the educational process largely depend on the teacher. On the contrary, the practice of blended learning shows that in this form of education the volume of learning material increases due to the flexibility of the learning model and more rational use of time in the classroom due to a preliminary study of educational material by using ICT.

In those cases when regular face-to-face meetings of a teacher and students of a distance course are possible, blended learning can be one of the ways to improve the efficiency of the educational process. The undeniable advantages of distance learning are: the flexibility of the learning model, information accessibility, interactivity, temporal asynchrony of learning, the massive nature of learning.

Noting the "weaknesses" of distance learning, it is worth emphasizing the lack of real communication between the teacher and the students, and as a result, the limited methods of pedagogical interaction, as well as personal interaction between the students. The lack of personal communication practically deprives the teacher of the possibility of using nonverbal and other methods of pedagogical influence, except for those cases when video courses, video conferences, etc. 
are used. These forms of teaching are currently beginning to find wide application in distance courses. Blended learning in this case allows you to restore direct contact of participants in the pedagogical process, to use non-verbal methods of communication. One of the problems of distance learning is also the insufficient formation of the ability of some students to learn independently by means of electronic technologies, which leads to an uneven distribution of workload during the period of study. In addition, we may assert that the use of ICT improves students' computer skills, while increasing the opportunities for academic and professional success of participants of the educational process. It is obvious that the ability to use new electronic technologies significantly affects a person's competitiveness in the labor market.

Blended learning implies the presence of introductory full-time classes to get acquainted with the specifics of the model and technologies which are used by the teacher. It is possible to overcome difficulties in mastering the material in the independent work, as students can clarify difficulties in the classroom. In this way, the teacher may plan the lesson taking into account the individual needs of the students and making the learning process more flexible [18].

Our experience in the use of ICT in teaching foreign languages has led to the creation of a number of integrated courses in the educational process. Analysis of practical implementation of supporting model of blended learning in teaching foreign languages to technical engineers has shown that it is one of the most productive forms of learning.

\subsection{Replacement model of blended learning}

The replacement model, in our opinion, most accurately reflects the essence of blended learning. It assumes the full integration of electronic educational resources into a training course, due to which a change in the format of the course as a whole occurs (the division of material and types of training activities between the distant and full-time component, the ratio can vary in the range from $30 \%-70 \%$ ). While maintaining the original amount of learning content, there is a reduction in classroom hours, the amount of time allotted for independent work increases.

The division into full-time and distant components entails a change in the forms of work in classroom and network classes. Full-time form in this model provides training course consultations with the teacher on the most difficult problems arising during the study of new material, conducting various kinds of discussions, debates, role-playing games, activity in small groups, doing practical and laboratory work, defense of projects. These are such activities that require direct contact of students with each other or with the instructor [19].

Distance component of such a model contains an informative module: general information about the course, its goals and objectives, structure, curriculum, class schedule, deadlines, etc., and also includes independent work on searching and processing information on the Internet, individual assignments with reference and information materials, communication between students, consultations with a teacher, current monitoring (tests), etc.

The described model is successfully implemented, if the information and educational environment of a university is well developed. The distribution of material, as well as types of learning activities between the full-time and distant components takes place in accordance with didactic tasks that it is advisable to solve in one form or another, the specificity of the subject is taken into account, the students and the teacher have well developed information competence and they are familiar with the specifics of this learning model.

Following these key positions provides effective design of the replacement educational model that makes the learning process more interesting, productive and open to students. It is also important to obtain information about communication environment, the relationship within the study group and students' attitude to the teacher and used methodology. To obtain such analytical data you should not only use traditional written worksheets, but also elaborate special mobile electronic questionnaires, which combine the features of "pedagogical" and "psychological" inquirers.

Thus, the effectiveness of such training we interpret as the achievement of didactic goals set for students. We emphasize the principle of learning effectiveness which determine correlation between educational goals and results. This approach reveals functioning and optimization of many factors that have a direct impact on the didactic process: interactive methods of teaching and students' way of learning, the level of mental development and students' personal abilities, reduction of time costs. All these points lay between the objectives of blended learning and students educational achievements.

In our opinion, such approach to replacement model of blended learning for teaching foreign language to technical engineers widely covers the concept under consideration, being a generalization of the above positions. Taking into account the learning efficiency factor, it seems appropriate to assume that blended learning can improve the learning process productivity due to the following factors:

- learning model flexibility;

- development of critical thinking and the ability to learn independently;

- accounting of individual psychological characteristics of students;

- providing regular feedback between all participants in the pedagogical process;

- more rational use of time in the classroom due to preliminary study of educational material through ICT;

- increase of the learning material amount;

- variation of pedagogical impact methods;

- modern pedagogical technologies reflecting the principles of the student-cetered approach;

- interactivity of the model;

- development of the students' information competence;

- the possibility of practically unlimited access to information for teachers and students. 


\subsection{Mobile model of blended learning}

The concept of blended learning suggest the possibility of optimal combination and using advantages of the full-time traditional educational and distance learning technologies that is a very valuable characteristic. It can be a real way to improve educational process effectiveness as in the framework of traditional education, which implies the classroomlearning system, and in the framework of distance learning with the modular system for the educational process design.

First of all, we should identify the meaning of the notion 'mobility of the educational process', and how it will be evaluated.

In this study we interpret this concept in several ways:

-quality of learning improvement along the reduction of time costs;

-mobility is not only the effect of flexiblele learning system where a student get specific skills improvement within a standard or special program but general soft skills including intellectual and personal development along with the professional competence development of a the teacher.

The effectiveness of mobile training is determined by internal and external criteria.

Internal criteria are:

- $\quad$ successful learning;

- academic progress;

- quality of knowledge;

- $\quad$ degree of skills development;

- level of students' personal development;

- professional competence progress;

- learning skills formation.

External criteria for determination of the learning process effectiveness:

- degree of graduate adaptation to social life and professional activities;

- the growth rate of the self-education process as a prolonged effect of learning;

- level of professional education;

- willingness to improve education;

- level of professional skills.

We suggest that effectiveness of mobile learning also involves collaboration and cooperation between students and teachers in the field independent activities planning and monitoring. That is why the effectiveness of learning process we interpret as the achievement of professional didactic goals that the learner faces.

In this connection evaluation of the effectiveness of training can be carried out in various ways. The simplest and most traditional way is the control of students' knowledge and skills conducted with the help of different tests, examinations, reports, educational projects, exams, etc. With such assessment of knowledge, you can get a more or less objective picture of the learning outcomes of each student and the group as a whole. However, when organizing the educational process in the form of mobile blended learning it is essential to take into account the following aspects:

- effectiveness of full-time and distance learning components combination in a training course;

- methods of selection and use of ICT in the educational process;

- convenience of training materials posted on the web;

- productiveness of the classroom training;

- effectiveness of online communication between teacher and students.

Thus, we may identify the main characteristics of mobile blended learning model:

- flexibility of learning process;

- open access to learning material;

- interactivity of learning communication

- temporary asynchronous learning, etc.

It should be noted that, taking into account the specifics of a particular discipline, mobile blended learning can improve the efficiency of the educational process in many subject areas, including the field of applied linguistics. This fact is based on the information and communication technologies capabilities to produce special didactic properties founded on two important functions - information and communication, the use of which helps in the most optimal and effective way to solve didactic tasks in the educational process. These properties are: multimedia, interactivity, communication, adaptability, productivity, creativity, the ability to control students' activities, both in real time and asynchronously, etc.

Mobile blended learning provide:

- forming of communication skills and communication culture;

- creation of authentic language environment with an aim to use a foreign language for the real practical purposes;

- skills and abilities development enabling to work with technical information;

- constant feedback, etc.

Mobile Blended learning model is based on the flexible interaction of students with each other and with the teacher, both in the computer environment and in the classroom. At the same time, the learning material developed independently is used in real situations of communication by solving communicative tasks, which contributes to the development of communicative competence, that is the main goal of teaching a foreign language nowadays. 


\subsection{Electronic linguistic center model}

The model of electronic linguistic center implies the creation of large university computer laboratories and information educational environments, which in the future may be able to completely change the understanding of the forms of education. This model is implemented in the information electronic environment of the university. The traditional classroom lessons take the form of compulsory full-time classes in the form of consultations, both group and individual, which are held in computer classes. In this regard, forms of education and the roles of the participants of the pedagogical process are also changing. The teacher becomes an advisor who organizes and coordinates the educational process rather than transferring educational information to students, and the student acquires the status of a subject of the educational process [20].

Implementation and successful functioning of the considered training model is possible with a developed university infrastructure, a pedagogically effective design of the information educational environment, qualified technical personnel, sufficient information literacy of all participants of the pedagogical process, a high degree of autonomy, formed sustainable motivation of students for learning and cognitive activity, information security of training.

Today there is no unified classification of blended learning models, which is largely due to the lack of a universally accepted definition of this concept. However, this does not prevent a steady increase in the number of attempts to use individual development of blended learning models in the educational process [21].

\section{Results of pedagogical experiment}

We conducted pedagogical experiment aimed the development of the communicative foreign language competence of technical students who studied in Saint-Petersburg polytechnic university. We elaborated training linguistic course based on the supporting model of blended learning and in the form of traditional classes in several institutes of Peter the Great Polytechnic university and worked with the students of the following Master's Degree Programs: mathematics and mechanics, computer and information science, physics and astronomy, architecture, computer science and engineering, electronics, radio and communication systems, electrical and heat power engineering, nuclear power and technology, mechanical engineering. First of all, we conducted the survey. Master students of the first course took part in this survey. The questionnaire consisted of 15 questions. The main issue we wanted to know: do students use information technologies in their studies, if so, which ones; do they think that it necessary to actively use the electronic educational environment when learning a foreign language, etc.

The survey involved 782 students. As a result, it was revealed that almost $100 \%$ of students actively use ICT in their educational activities. Moreover, almost all the surveyed students are ready to actively use ICT when learning a foreign language. We also included questions that reveal students' level of proficiency in technical English. The level of development of communicative competence was determined on the basis of the test control. Tests included tasks for which students received points. The test results are presented as the percentage: the number of received points from possible $100 \%$ (table 1$)$.

\begin{tabular}{|l|l|l|}
\hline Master's Degree Programs & $\begin{array}{l}\text { Control } \\
\text { groups }\end{array}$ & $\begin{array}{l}\text { Experimental } \\
\text { groups }\end{array}$ \\
\hline Mathematics and mechanics & $47,5 \%$ & $45,4 \%$ \\
\hline Computer and information science & $63,2 \%$ & $61,7 \%$ \\
\hline Physics and astronomy & $51,3 \%$ & $54,4 \%$ \\
\hline Architecture & $49,8 \%$ & $52,6 \%$ \\
\hline Computer science and engineering & $64,4 \%$ & $63,9 \%$ \\
\hline Electronics & $65,6 \%$ & $62,8 \%$ \\
\hline Radio and communication systems & $56,1 \%$ & $57,2 \%$ \\
\hline Electrical and heat power engineering & $48,3 \%$ & $46,9 \%$ \\
\hline Nuclear power and technology & $47,6 \%$ & $49,1 \%$ \\
\hline Mechanical engineering & $44,5 \%$ & $43,8 \%$ \\
\hline
\end{tabular}

Table 1. The level of students' proficiency in technical English at the initial phase of the experiment

Developing experimental training, we have identified 5 main stages of the educational experiment based on the supporting model of blended learning:

1. analytical stage;

2. goal-setting stage;

3. development stage;

4. implementation stage;

5. rating stage. 


\subsection{Content of the analytical stage}

1. Study of the socio-communicative context of blended learning application in higher education in general and in linguistic education, in particular; review of the actual engineering education goals.

2. Analysis of the characteristics, needs and requirements of the target audience, due to the specifics of the learning environment and real experience of learning a foreign language: consideration of age and individual characteristics of students, the initial level of skills and abilities, their level of general and information culture, motivation for cognitive activities, etc. At this stage, we can recommend the conduct of diagnostic tests to identify and analyze the above features of needs, as well as the use of such research methods as: interviews, surveys, questionnaires, etc.

3. Accounting of principal characteristics of educational environment caused by objective and subjective factors of its development: the compliance of the declared forms of education in the university with the actually implemented; the development of the information educational environment of the university; capacity to attract additional ICT support (moderators and course developers), computer literacy of the educational process members and potential opportunities for its improvement (conducting seminars and trainings devoted to the information competence development). It is also important to determine the topic of the course, its duration, assignment (basic course, elective course, etc.), the possibility of integration with other courses.

\subsection{Content of the goal-setting stage}

The formulation of the general objectives of the course and specific tasks, explaining the purpose and determining the result of training. The choice of the blended learning model. For example, when designing Supporting model of blended learning we should pay attention to the distribution of hours between the full-time and distant components, the definition of goals, the sequence and frequency of alternation of modules in accordance with the specifics of the educational environment and the target audience. In other words, at this stage a general concept of the course is being formed.

\subsection{Content of the development stage}

This phase is the most complicated and time-consuming. It includes:

1. elaboration of the course content (topics of sections, problems for discussion, determination of the lexical and grammatical corpus of topics, socio-cultural material, etc.);

2. the choice of specific methods and techniques, forms of activities, types of educational tasks;

3. optimal selection of ICT caused by the methodological feasibility of its inclusion in the educational process and real technical capabilities.

4. distribution of educational material between full-time and distant components.

At this stage, it is necessary to analyze selected training materials (not only the basic teaching materials, but also information materials on the Internet), activities that are more effective for work in full-time and distant formats, determine the functions of the full-time and distance components.

Full-time component includes:

- familiarization of students with the specifics of work within the blended learning model;

- group discussion of the goals of this course, the problems studied and ways of their solutions in the introductory classes;

- familiarization of students with new material that requires the direct participation of the teacher (for example, difficult grammatical phenomena, language phenomena that require a cultural reference);

- activity in small groups to train various types of speech (discussions, disputes, role-playing games, etc.);

- presentations and defense of projects;

- tests, examinations, etc.

Distance learning component includes:

- independent research work on the Internet;

implementation of additional tasks, assignments of different levels of complexity, etc. (differentiated learning);

- joint fulfillment of creative and research assignments, the presentation of intermediate results and the progress of implementation;

- work with reference materials, information resources, educational materials (materials containing general information about the course, timetable, prepared materials on grammar, vocabulary, additional texts for reading and listening, materials for project activities, a glossary, links to useful resources on the topic being studied etc.)

- entry and final tests;

- communication within the course by the means of various ICT (e-mail, news forum, discussion forum, chat rooms, video conferencing, blogs, etc.)

5. Elaboration of the content and forms of current, intermediate and final control, including the definition of parameters and criteria of assessment. Within the blended learning current, intermediate and final control can be carried out in the traditional form in the classroom in the form of various types of examination works, defense of projects ets. In the distance component separate types of intermediate testing and tasks for self-control can be used.

6. Development of parameters and criteria for evaluating the effectiveness of the designed model. 


\subsection{Implementation stage}

The fourth stage is the direct implementation and testing of the designed model of blended learning of the technical English. This stage involves the integration of the results of the previous stages into the learning process and may be represented in coordination of the educational process, which involves regular updating of information (distance component), constant feedback, encouraging productive interaction between students etc. Many teachers note that the inclusion of the distance component in the educational process [3, 16, 20, 22] almost inevitably entails technical problems, the solution of which must be quick and with minimal damage to the educational process. In this regard, teachers should always have a backup version of the lesson plan in case technical problems arise and warn students about them as far as possible in advance.

\subsection{Rating stage}

The last stage of the proposed algorithm is associated with an assessment of the pedagogical effectiveness of the created model. Continuous monitoring of the effectiveness of the educational process is the key to the successful implementation of blended learning, as it allows you to adjust and improve pedagogical process, both during the educational process and after its completion. Despite the fact that evaluation is the last stage in the above algorithm, it should not be considered as the end of the process of designing a blended learning model, since the results of this particular stage lead to a revision of the above-mentioned steps of the algorithm. In other words, planning and organizing this pedagogical model is a cyclical process, where the last stage (assessment) is considered not as the end of the process, but as the starting point of a cycle.

At the end of the experiment, which lasted six months, at the final stage, we diagnosed the level of development of students' communicative competence. The results of testing proved the effectiveness of the developed methodology of teaching technical English on the basis of blended learning. Data is presented in the table below (Table 2).

\begin{tabular}{|c|c|c|}
\hline Master's Degree Programs & Control groups & $\begin{array}{c}\text { Experimental } \\
\text { groups }\end{array}$ \\
\hline Mathematics and mechanics & $51,4 \%$ & $79,6 \%$ \\
\hline Computer and information science & $66,3 \%$ & $82,8 \%$ \\
\hline Physics and astronomy & $55,6 \%$ & $83,7 \%$ \\
\hline Architecture & $54,2 \%$ & $85,3 \%$ \\
\hline Computer science and engineering & $68,7 \%$ & $89,4 \%$ \\
\hline Electronics & $68,5 \%$ & $91,2 \%$ \\
\hline Radio and communication systems & $61,4 \%$ & $92,3 \%$ \\
\hline Electrical and heat power engineering & $51,9 \%$ & $78,7 \%$ \\
\hline Nuclear power and technology & $52,4 \%$ & $78,5 \%$ \\
\hline Mechanical engineering & $49,6 \%$ & $77,3 \%$ \\
\hline
\end{tabular}

Table 2. The level of students' proficiency in technical English at the final phase of the experiment

The data presented in the diagram (Figure 1) confirm the effectiveness of our experimental work. Test control has made it possible to determine a significant increase in the level of students' communicative competence development in the experimental group. Thus, the conducted experimental work confirmed the effectiveness of the supporting model of blended learning in foreign languages education of engineering students. 


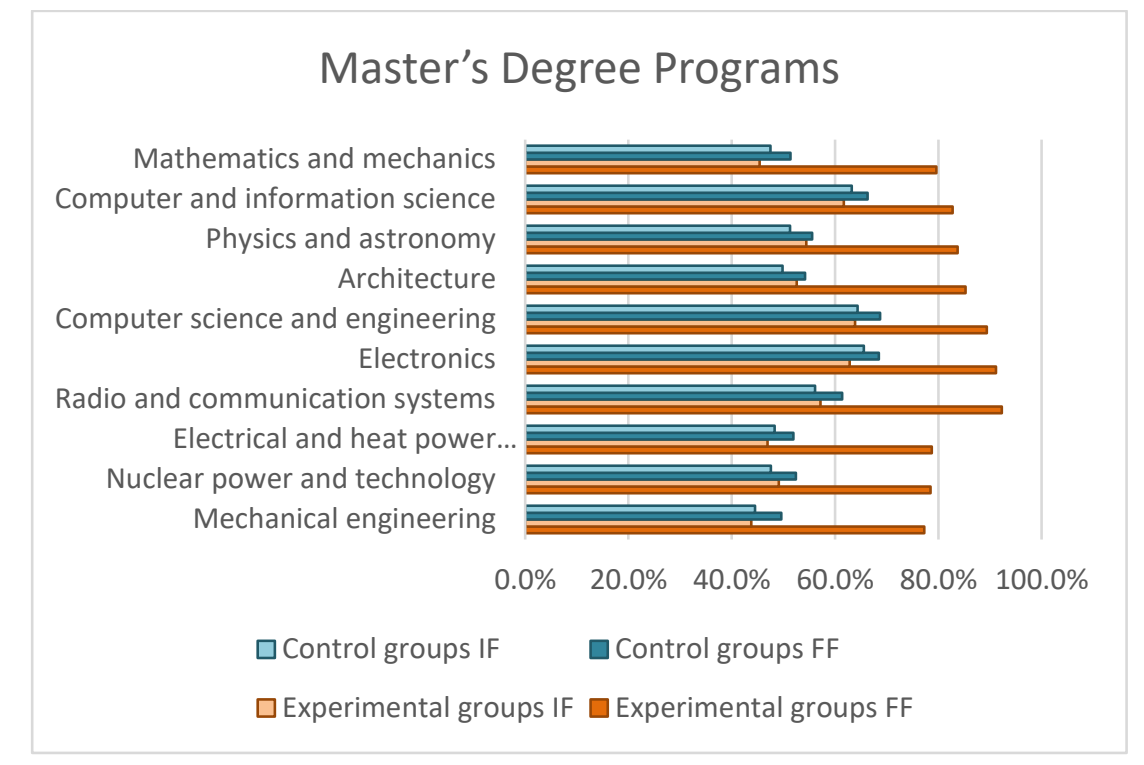

Fig. 1. Comparative analysis of the technical English level at the initial and final stages of learning

\section{Conclusion}

Elaboration of training courses in the form of blended learning or modification (transition from the traditional form of education to a mixed one) of existing ones can be carried out both within a separate course and within the framework of a unified system of transformation of all training courses of the department, faculty or university. In any case, the development or modernization of such courses should be carried out in accordance with didactic principles, psychological and pedagogical aspects, as well as the conditions for integrating blended learning into the educational process and provide the sequential passing of several stages inherent in the design of any learning model in the training system of engineers.

The main differences in the design of the blended learning model from traditional learning can be considered the choice of a blended learning model relevant to the goals, objectives and learning conditions, information and communication technologies as learning tools used in this model, as well as the distribution of educational material, types of cognitive activities and forms of work between face-to-face and distance component. Highlighted regulations can be considered the key to the creation or modification of any course within the blended learning model in the training system of engineers. In this research, we solved the problem of improving the quality of foreign languages training of technical engineers by the means of blended learning modelling according to main factors of implementation: university level, teacher level and student level factors.

We analyzed different types of blended learning models: supporting, replacement, mobile and electronic linguistic center models. Our methodological analysis showed that the most appropriate technique in conditions of Russian Higher Education is supporting model of blended learning. The flexibility of this training model implies the ability to work with educational material at a convenient time with a comfortable pace. The advantage of blended learning in this case is the combination of independent learning with classroom instruction, i.e. the student does not experience a lack of personal communication with the teacher and other students, while being able to work at an individual pace. The blended learning model positively affects students' ability to independently navigate the flow of information, select and structure necessary material for training and personal development. In other words it develops students' learning autonomy as the ability to critical reflection, decision-making and independent activity.

The main result of this research is the communicative foreign language competence development of the technical students who studied in Saint-Petersburg polytechnic university. Developing experimental training, we have identified 5 main stages of the educational experiment based on the supporting model of blended learning: analytical, goal-setting, development, implementation and rating stages. We elaborated training linguistic course based on the supporting model of blended learning in several institutes of Peter the Great Polytechnic university and worked with the students of the following Master's Degree Programs: mathematics and mechanics, computer and information science, physics and astronomy, architecture, computer science and engineering, electronics, radio and communication systems, electrical and heat power engineering, nuclear power and technology, mechanical engineering. The results of testing proved the effectiveness of the developed methodology of teaching technical English on the basis of blended learning. Thus, we solved the problem of students' proficiency development in technical English.

Further justification of teaching technical English on the basis of blended learning will provide communicative foreign language competence development. The next step of our methodological concept development based on the blended learning implementation in technical university will be associated with detailed educational linguistic content. 
This stage of research will lead to the advanced context of foreign languages training of technical engineers by the means of blended learning modelling including undergraduate level of education.

\section{References}

[1] Solovova, E. N. (2006) Methods of Teaching Foreign Languages: A Basic Course of Lectures: A Handbook for Students of Ped. universities and teachers. - 4th ed. (Moscow: Enlightenment), 239.

[2] Valiathan, P. (2002) Blended Learning Models http://www.learningcircuits.org/2002/aug2002/valiathan.html (accessed 14 November 2011).

[3] Sharma. P., Barett B. (2007) Blended Learning (Books for Teachers) (Macmillan ELT), 160.

[4] Zarske, Malinda S.; Cunitz, Jaclyn L.; Forbes, Marissa H.; Sullivan, Jacquelyn F. (2015) General Engineering Plus: Creating Community in a Flexible yet Technical Engineering Degree. Proceedings of the ASEE Annual Conference \& Exposition, p1-18. 18p.

[5] Czarnecki, L., Van Gemert, D. Bulletin of the Polish Academy of Sciences (2017) Civil Engineering - Ongoing Technical Research. Part 2. Technical Sciences, Vol. 65 Issue 6, p761-763. 3p. DOI: 10.1515/bpasts-2017-0082.

[6] Litchfield, K., Javernick W. (2016) Technical and Professional Skills of Engineers Involved and Not Involved in Engineering Service. Journal of Engineering Education. Vol. 105 Issue 1, p70-92. 23p.

[7] Desyatova, L.V. (2010) The use of Blended Learning model to create and test the ICT course supporting the training according to the basic program / / Information and communication technologies in linguistics, linguodidactics and intercultural communication. Art. / ed. A.L. Nazarenko (Moscow: Center Distance. Education: Fac. Of foreign lang. and regional studies of the Moscow State University), Vol. 4., 81-90.

[8] Kumar, S. Tammelin M. (2008) Integrating ICT into language learning and teaching. Guide for Institutions (Johannes Kepler Universität Linz, Altenberger Straße 69, 4040 Linz), 43.

[9] Almazova, N \& Barinova, D \& Ipatov, O (2018). Forming of Information Culture With Tools of Electronic Didactic Materials, Proceedings of the 29th DAAAM International Symposium, pp.0587-0593, B. Katalinic (Ed.), Published by DAAAM International, ISBN 978-3-902734-20-4, ISSN 1726-9679, Vienna, Austria DOI: 10.2507/29th.daaam.proceedings.085.

[10] Horn, M.B., \& Staker, H. (2015). Blended: Using Disruptive Innovation to Improve Schools, Jossey-Bass, ISBN 978-1118955154, San Francisco, CA, USA.

[11] Rubtsova, A., Almazova, N. (2019) Productive Model of Foreign Languages Learning: Realities and Prospects. Advances in Social Science, Education and Humanities Research, volume 289. International Conference on Communicative Strategies of Information Society (CSIS 2018) https://www.atlantis-press.com/proceedings/csis18/55913842 (accessed on 25 February 2019).

[12] Alammary, A., Sheard, J., \& Caebone, A. (2014). Blended learning in higher education: Three different design approaches. Australasian Journal of Educational Technology, Vol. 30, No. 4, pp. 440-454, DOI 10.14724/ajet.693.

[13] Powel, A., Rabbitt, B., \& Kennedy, K. (2014). iNACOL blended learning teacher competency framework, Available from: https://www.inacol.org/wp-content/uploads/2015/02/iNACOL-Blended-Learning-Teacher-CompetencyFramework.pdf, Accessed: 2019-03-26.

[14] Oblinger, D., Oblinger, J. (2005) Is It Age or IT: First Steps Toward Understanding the Net Generation. http://www.net.educause.edu/ir/library/pdf/pub7101b.pdf (accessed 12 May 2011).

[15] Technical Translation Center. ASE "Radio Frequency Center MO" / Dictionaries / Sleng / Digital native. http://www.rfcmd.com (accessed 26 February 2019).

[16] Khomchenko, V. K., Gebel, E. S., \& Peshko, M. S. (2018). Educational robotics as part of the International Science and Education Project "Synergy" in realizing the social needs of society on the road to the Industrial Revolution "Industry 4.0." EAI Endorsed Transactions on Energy Web, 5(16), 153816. doi:10.4108/eai.30-1-2018.153816.

[17] Butenkova, E.V. (2008) Methodical foundations of creating an integrated foreign language course in specialized classes of a secondary school / / Information and communication technologies in teaching foreign languages and intercultural communication: Coll. Art. / ed. A.L. Nazarenko (Moscow: Centruchebfilm), Vol. 3, 196-204.

[18] Evdokimova, M.G. (2008) The principle of unity of learning and development of the student in terms of the application of information and communication / / Information and communication technologies in teaching foreign languages and intercultural communication: Coll. Art. / ed. A.L. Nazarenko (Moscow: Centruchebfilm), Vol. 3, 1626.

[19] Allen, I.E., Seaman, J., and Garrett, R. (2007) Blending in: The extent and promise of blended education in the United States. http://www.sloanconsortiiim.org/publications/survev/pdf/Blending In.pdf (accessed 11 April 2011).

[20] Bersin, J. (2004) The Blended Learning Book: Best Practices, Proven Methodologies, and Lessons Learned (Pfeiffer John Wiley \& Sons), 319.

[21] Clark, D. (2003) Blended Learning (CEO Epic.

[22] Rubtsova, A.V. (2018) Socio-linguistic innovations in education: productive implementation of intercultural communication. In Proceedings of International Scientific Conference "Digital Transformation on Manufacturing, Infrastructure and Service", IOP Conference series: Material science and engineering, vol. 497; St. Petersburg, Russian Federation, 1-22 November 2018; Sergeev V. (ed); IOP, 2018; 012059. Available https://iopscience.iop.org/article/10.1088/1757-899X/497/1/012059/pdf (accessed on 11.04.2019). 